VNU Journal of Science: Legal Studies

Journal homepage: https://js.vnu.edu.vn/LS

\author{
Review Article
}

\title{
Recognition and Enforcement of Foreign Arbitral Awards Under the 2015 Civil Procedure Code and Recommendations for Improving the Efficiency of Law Application in Vietnam
}

\author{
Banh Quoc Tuan* \\ Faculty of Law, Ho Chi Minh City University of Technology, \\ 475A, Dien Bien Phu, Binh Thanh, Ho Chi Minh City, Vietnam \\ Received 13 August 2019 \\ Revised 25 August 2019; Accepted 19 September 2019
}

\begin{abstract}
Studying the process of applying the provisions of the Civil Procedure Code on the recognition and enforcement of foreign arbitral awards, this review made comments on the regulations of the law as well as analyzed the problems arising from the application of the law in practice for proposing some recommendations to improve the law.
\end{abstract}

Keywords: International judiciary, foreign arbitral award, recognition and enforcement of foreign arbitral awards.

\footnotetext{
* Corresponding author.

E-mail address:bq.tuan@hutech.edu.vn
}

https://doi.org/10.25073/2588-1167/vnuls.4235 


\title{
Thực tiễn công nhận và cho thi hành tại Việt Nam phán quyết của trọng tài nước ngoài theo Bộ luật Tố tụng dân sự 2015 và kiến nghị góp phần nâng cao hiệu quả điều chỉnh của pháp luật
}

\author{
Bành Quốc Tuấn* \\ Khoa Luật, Trường Đại học Công nghệ Thành phố Hồ Chí Minh \\ 475A, Điện Biền Phủ, Quận Bình Thạnh, Thành phố Hồ Chí Minh, Việt Nam \\ Nhận ngày 13 tháng 8 năm 2019 \\ Chỉnh sửa ngày 25 tháng 8 năm 2019; Chấp nhận đăng ngày 19 tháng 9 năm 2019
}

\begin{abstract}
Tóm tắt: Trên cơ sở nghiên cứu quá trình áp dụng quy định của Bộ luật Tố tụng dân sự 2015 về công nhận và cho thi hành tại Việt Nam phán quyết của Trọng tài nước ngoài, tác giả đã đưa ra những nhận xét về quy định của luật cũng như phân tích những vấn đề phát sinh từ quá trình áp dụng pháp luật vào thực tiễn làm cơ sở cho việc đề xuất một số kiến nghị góp phần hoàn thiện pháp luật.
\end{abstract}

Tù khóa: Tư pháp quốc tế, phán quyết của trọng tài nước ngoài, công nhận và cho thi hành phán quyết của trọng tài nước ngoài.

\section{1. Đặt vấn đề}

Công nhận và cho thi hành phán quyết của Trọng tài nước ngoài là một nội dung quan trọng của hoạt động tương trợ tư pháp và là một trong những nội dung của Tư pháp quốc tế các nước. Sự điều chỉnh pháp luật về công nhận và cho thi hành tại Việt Nam phán quyết của Trọng tài nước ngoài hiện nay tập trung tại Bộ luật Tố tụng dân sự 2015 và một số văn bản pháp luật liên quan. Thực tiễn áp dụng các quy định này từ thời điểm Bộ luật Tố tụng dân sự

\footnotetext{
*Tác giả liên hệ.

Địa chỉemail:bq.tuan@hutech.edu.vn

https://doi.org/10.25073/2588-1167/vnuls.4235
}

2015 có hiệu lực thi hành $(01 / 7 / 2016)$ cho thấy tính phù hợp của quy định pháp luật với thực tiễn yêu cầu công nhận và cho thi hành các phán quyết của Trọng tài nước ngoài, góp phần quan trọng thúc đẩy các quan hệ kinh doanh, thương mại có yếu tố nước ngoài.

Tuy nhiên, trong bối cảnh tình hình kinh tế xã hội thay đổi nhanh chóng, quá trình hội nhập quốc tế diễn ra ngày càng mạnh mẽ, từ thực tiễn áp dụng pháp luật đã phát sinh một số vấn đề cần tiếp tục được nghiên cứu để nâng cao hiệu quả điều chỉnh của pháp luật. Trong bài viết, tác giả đã áp dụng phương pháp phân tích để làm rõ bốn nội dung: Phán quyết của Trọng tài nước ngoài được công nhận tại Việt Nam; Nguyên tắc công nhận và cho thi hành tại Việt Nam 
phán quyết của Trọng tài nước ngoài; Điều kiện công nhận và cho thi hành tại Việt Nam phán quyết của Trọng tài nước ngoài; Cơ quan có thẩm quyền nhận đơn yêu cầu công nhận và cho thi hành tại Việt Nam phán quyết của Trọng tài nước ngoài. Đồng thời, tác giả sử dụng phương pháp tổng hợp để trình bày tình hình thực tiễn có liên quan đến các vấn đề trên làm cơ sở cho các kiến nghị góp phần nâng cao hiệu quả điều chỉnh của pháp luật trong giai đoạn sắp tới.

\section{Nội dung điều chỉnh của Bộ luật Tố tụng dân sự 2015 về công nhận và cho thi hành tại Việt Nam phán quyết của Trọng tài nước ngoài}

\subsection{Phán quyết của Trọng tài nước ngoài được công nhận tại Việt Nam}

Khoản 2 Điều 425 Bộ luật Tố tụng dân sự 2015 về "Phán quyết của Trọng tài nuớc ngoài được công nhận và cho thi hành tai Việt Nam" quy định: Phán quyết của Trọng tài nước ngoài được xem xét công nhận và cho thi hành tại Việt Nam là phán quyết cuối cùng của Hội đồng trọng tài giải quyết toàn bộ nội dung vụ tranh chấp, chấm dứt tố tụng trọng tài và có hiệu lực thi hành. Theo khoản 10 Điều 3 Luật Trọng tài thương mại 2010 thì: "Phán quyết trọng tài là quyêt định của Hộ đồng trong tài giải quyết toàn bộ nội dung vu tranh chấp và chấm dưt tố tụng trọng tài”. Khoản 2 Điều 424 Bộ luật Tố tụng dân sự 2015 sử dụng thuật ngữ "phán quyết cuối cùng" để chỉ phán quyết trọng tài này. Quy định của Bộ luật Tố tụng dân sự 2015 tương đồng với quy định của Công ước New York 1958 về công nhận và thi hành phán quyết của Trọng tài nước ngoài (gọi tắt là Công ước New York 1958) mà Việt Nam đã là thành viên từ ngày 28/7/1995. Theo khoản 2 Điều 1 Công ước New York 1958 thì: "Thuật ngũ quyêt định trọng tài bao gồm không chỉ những quyết định được tuyên bởi các Trọng tài viên được chỉ định cho tùng vu mà còn bao gồm nhũng quyết định được tuyên bởi các tổ chức trong tài thuoòng trưc được các bên đưa vu việc ra giải quyết". Trong quyết định của Toà án Việt Nam công nhận và cho thi hành phán quyết của Trọng tài nước ngoài cũng sử dụng thuật ngữ "phán quyết cuối cùng" giải quyết vụ việc để chỉ loại phán quyết chính thức này.

Ví dụ: Quyết định số 01/2019/QĐSTKDTM ngày 15/02/2019 của Toà án nhân dân tỉnh Long An về "Xét đơn yêu cầu công nhận và cho thi hành tại Việt Nam phán quyết của Trọng tài nuoớc ngoài" của người được thi hành là Ngân hàng Trách nhiệm hữu hạn một thành viên Standard Chartered - Việt Nam (gọi tắt SCB Việt Nam), địa chỉ trụ sở tại P1810-P1815, Keangnam Hanoi Landmard, E6, Phạm Hùng, phường Mễ Trì, quận Nam Từ Liêm, Hà Nội và người phải thi hành là Công ty Cổ phần NIVL (gọi tắt là Công ty NIVL), địa chỉ trụ sở tại ấp 6, xã Lương Hòa, huyện Bến Lức, tỉnh Long An và Công ty Cổ phần đường Bình Định (gọi tắt là Công ty đường Bình Định), địa chỉ trụ sở tại Km52, Quốc lộ 19, xã Tây Giang, huyện Tây Sơn, tỉnh Bình Định, Toà án đã sử dụng thuật ngữ "Phán quyết cuối cùng" để chỉ Phán quyết trọng tài ngày 14/05/2018 (đăng ký trong sổ đăng ký phán quyết SIAC là Phán quyết số 055 năm 2018 ngày 15/05/2018) của Hội đồng trọng tài thuộc Trung tâm trọng tài quốc tế Singapore. Tương tự, Quyết định số 127/2018/QĐKDTM - ST ngày 29/01/2018 của Toà án nhân dân thành phố Hồ Chí Minh về "Công nhận và cho thi hành tại Việt Nam phán quyết của Trọng tài nước ngoài" giải quyết yêu cầu của người được thi hành là Công ty $\mathrm{TNHH}$ Pan Ocean, địa chỉ trụ sở chính tại Tower 8,7 Jong - ro 5- Gil, Jongno - gu, Seoul, Hàn Quốc và người phải thi hành là Công ty Cổ phần Tập đoàn Vạn An, địa chỉ trụ sở chính tại 129 đường 59 , phường 14 , quận Gò Vấp, thành phố Hồ Chí Minh, Toà án đã sử dụng thuật ngữ "Phán quyết trong tài cuối cùng" để chỉ phán quyết của trọng tài Alan Oakley ngày 21/6/2017 của Hiệp hội trọng tài Hàng hải Luân Đôn thuộc Vương quốc Anh.

Như vậy, theo Bộ luật Tố tụng dân sự 2015, phán quyết của Trọng tài nước ngoài được công nhận và cho thi hành tại Việt Nam là phán quyết bằng văn bản, được tuyên bởi Hội đồng trọng tài, mục đích để giải quyết toàn bộ các nội 
dung liên quan đến yêu cầu của các bên tham gia vụ việc giải quyết tại trọng tài. Phán quyết này là kết quả của quá trình Hội đồng trọng tài xem xét yêu cầu của các bên, cơ sở để bảo vệ yêu cầu của các bên và theo một quy tác tố tụng trọng tài nhất định. Nói cách khác, phán quyết Trọng tài được tuyên trên cơ sở và phụ thuộc vào ý chí của Hội đồng trọng tài, trong đó nêu rõ quyền và nghĩa vụ của các bên. Có thể tạm sử dụng thuật ngữ "phán quyết chinh thức" để chỉ loại phán quyết trọng tài này. Đây là quy định kế thừa Bộ luật Tố tụng dân sự 2004 (sửa đổi, bổ sung 2011) và phù hợp với tình hình thực tiễn của Việt Nam.

Tuy nhiên, trên thế giới, bên cạnh phán quyết trọng tài chính thức, pháp luật của một số nước còn thừa nhận loại "phán quyết trọng tài phi chính thức" (lodo irrituale) là phán quyết ra đời từ cơ chế cho phép các bên tham gia vụ việc tại trọng tài được tự mình quyết định về các nội dung của vụ việc giải quyêt tại trọng tài. Italia là quốc gia điển hình về việc công nhận loại phán quyết trọng tài phi chính thức này. Theo pháp luật Italia, có hai loại quy trình tố tụng trọng tài: Quy trình trọng tài chính thức (arbitrato rituale) và quy trình trọng tài phi chính thức (arbitrato irrituale). Quy trình trọng tài chính thức là quy trình trọng tài thông thường được áp dụng rộng rãi, phổ biến trên toàn thế giới. Quy trình trọng tài phi chính thức là "quy trình hoàn toàn dựa trên sụ chủ động của các bên, và chính các bên, chứ không phải Hội đồng trọng tài, mói là người thiết lập nên phán quyết trọng tài nhằm giải quyết tranh chấp. Phán quyết được thiết lập dựa hoàn toàn vào ý chí của các bên và trọng tài chỉ đóng vai trò là người chứng kiến sự thoả thuận" [1-2]. Quy trình trọng tài phi chính thức không dẫn đến việc ban hành phán quyết trọng tài. Trong quá khứ, pháp luật Italia chỉ xem trọng tài phi chính thức như một hình thức tập quán trong giải quyết tranh chấp thương mại. Quá trình pháp điển hoá của pháp luật Italia đã dẫn đến việc ban hành các quy định cụ thể điều chỉnh loại trọng tài này [1]. Bộ luật Tố tụng dân sự 2015, Luật Trọng tài thương mại 2010 và các văn bản hướng dẫn thi hành đến thời điểm hiện tại chưa có bất cứ quy định nào liên quan đến loại phán quyết trọng tài phi chính thức này. Trong quá trình mở rộng các giao dịch thương mại, kinh doanh có yếu tố nước ngoài sẽ phát sinh tình huống loại phán quyết này được yêu cầu công nhận và cho thi hành tại Việt Nam thì giải pháp của Việt Nam là như thế nào, có cần ban hành quy định pháp luật điều chỉnh vấn đề công nhận và cho thi hành loại phán quyết trọng tài này tại Việt Nam hay không? Đây là vấn đề cần tiếp tục nghiên cứu trong giai đoạn sắp tới.

\subsection{Nguyên tắc công nhận và cho thi hành tại Việt Nam phán quyết của Trọng tài nuớc ngoài}

Điều 424 Bộ luật Tố tụng dân sự 2015 về"Phán quyết của Trọng tài nước ngoài được công nhận và cho thi hành tại Việt Nam" quy định hai nguyên tắc công nhận và cho thi hành tại Việt Nam phán quyết của Trọng tài nước ngoài:

Thư nhất, nguyên tắc có điều ước quốc tế. Nguyên tắc có điều ước quốc tế đã được quy định trong Bộ luật Tố tụng dân sự 2004 (sửa đổi, bổ sung 2011) tại khoản 2 Điều 343 và tiếp tục được kế thừa trong Bộ luật Tố tụng dân sự 2015. Yêu cầu này cũng là một thông lệ quốc tế và được quy định chính thức tại Nguyên tắc này cũng được ghi nhận tại Điều 1 Công ước New York 1958. Theo điểm a khoản 1 Điều 424 Bộ luật Tố tụng dân sự 2015 thì phán quyết của Trọng tài nước ngoài được xem xét công nhận và cho thi hành tại Việt Nam nếu nước đó và Việt Nam cùng là thành viên của điều ước quốc tế về công nhận và cho thi hành phán quyết của Trọng tài nước ngoài. Việt Nam đã là thành viên của Công ước New York 1958 nên về nguyên tắc Việt Nam sẽ công nhận và cho thi hành phán quyết của Trọng tài các nước là thành viên của Công ước. Tuy nhiên, một phán quyết của Trọng tài nước ngoài là thành viên của Công ước New York năm 1958 có được công nhận và cho thi hành tại Việt Nam hay không còn phụ thuộc vào các quy định cụ thể của pháp luật Việt Nam, mà cơ bản là các quy định của Bộ luật Tố tụng dân sự 2015 và Luật Trọng tài thương mại 2010. Theo các công trình 
nghiên cứu đã công bố thì nguyên tắc này được áp dụng chung cho công nhận và cho thi hành tại Việt Nam phán quyết của Trọng tài nước ngoài, bản án, quyết định dân sự của Toà án nước ngoài [2-6].

Trong giai đoạn áp dụng Bộ luật Tố tụng dân sự 2004, nguyên tắc có điều ước quốc tế đã được áp dụng nhiều lần trên thực tế để công nhận và cho thi hành tại Việt Nam phán quyết của Trọng tài nước ngoài cũng như bản án, quyết định dân sự của Toà án nước ngoài. Ví dụ, Quyết định số 45/2012/QĐST ngày 10/9/2012 của Toà án nhân dân thành phố Hà Nội "V/v công nhận và cho thi hành tại Việt Nam bản án, quyết định dân sư của Toà án nước ngoài" giữa bên được thi hành là bà Lưu Thị Tuyết Nh. (Nh. Lukomska), địa chỉ tại Hlonda 2 M 66, Warsaw, Poland và bên phải thi hành là ông Nguyên Bá Q., địa chỉ tại số 191 phố Đại La, phường Đồng Tâm, quận Hai Bà Trưng, Hà Nội, Hội đồng xét đơn yêu cầu đã áp dụng Điều 45 Hiệp định tương trợ tư pháp về các vấn đề dân sự, gia đình và hình sự giữa nước Cộng hoà xã hội chủ nghĩa Việt Nam và nước Cộng hoà Ba Lan ngày 22/3/1993 chấp nhận đơn yêu cầu công nhận và cho thi hành tại Việt Nam Bản án số III C 344/05 ngày 06/8/2007 của Toà án Varsaw, Poland của bà Nh. giải quyết ly hôn giữa bà $\mathrm{Nh}$. và ông $\mathrm{Q}$. Tương tự, Quyết định số 01/2014/QĐSTKDTM ngày $06 / 6 / 2014$ của Toà án nhân dân tỉnh Long An về "Xét đơn yêu cầu công nhận và cho thi hành tại Việt Nam quyết định của Trọng tài nước ngoài" giải quyết yêu cầu của người được thi hành là Cargill Cotton, một đơn vị kinh doanh của Cargill, Incorporated (Cargill), địa chỉ trụ sở chính tại 7101 Goodlett Farms Parkway Cordova, Tennessee 38016 USA, công nhận Quyết định trọng tài nước ngoài ngày $06 / 02 / 2013$ của Hội đồng trọng tài thuộc Hiệp hội bông quốc tế tại Liverpool, Anh Quốc, Hội đồng đã xác định vì cả nước Anh và Việt Nam đều là thành viên của Công ước New York 1958 nên áp dụng cơ sở pháp lý tại khoản 3 Điều 2 Bộ luật Tố tụng dân sự 2004 (sửa đổi, bổ sung 2011) để giải quyết yêu cầu.
Đến giai đoạn áp dụng Bộ luật Tố tụng dân sự 2015, nguyên tắc có điều ước quốc tế tiếp tục được áp dụng để công nhận và cho thi hành tại Việt Nam phán quyết của Trọng tài nước ngoài. Ví dụ, Quyết định số 127/2018/QĐKDTM - ST ngày 29/01/2018 của Toà án nhân dân thành phố Hồ Chí Minh về giải quyết yêu cầu của Công ty TNHH Pan Ocean (Hàn Quốc) yêu cầu công nhận Phán quyết của trọng tài Alan Oakley ngày 21/6/2017 của Hiệp hội trọng tài Hàng hải Luân Đôn thuộc Vương quốc Anh, Hội đồng đã chấp thuận yêu cầu của người được thi hành vì "nước Anh và Nước CHXHCN Việt Nam đều là thành viên của Công uó́c New York 1958 về công nhận và cho thi hành phán quyết của trọng tài nước ngoài".

Thư hai, nguyên tắc có đi có lại. Theo điểm $\mathrm{b}$ khoản 1 Điều 424 thì phán quyết của Trọng tài nước ngoài được xem xét công nhận và cho thi hành tại Việt Namtrên cơ sở nguyên tắc có đi có lại. Mặc dù đến thời điểm hiện tại đã có khoảng 159 quốc gia là thành viên của Công ước New York năm 1958 nhưng vẫn còn nhiều quốc gia chưa gia nhập. Trong tương lai có thể phát sinh yêu cầu công nhận và cho thi hành phán quyết của Trọng tài nước nước ngoài trên lãnh thổ Việt Nam và ngược lại mà nước đó chưa phải là thành viên của Công ước $\mathrm{New}$ York năm 1958 và giữa hai nước cũng không có thỏa thuận liên quan khác. Vì vậy, Bộ luật Tố tụng dân sự 2015 đã quy định nguyên tắc có đi có lại để mở rộng phạm vi các trường hợp công nhận và cho thi hành tại Việt Nam phán quyết của Trọng tài nước ngoài. Nguyên tắc có đi có lại còn là cơ sở để Việt Nam bảo vệ các lợi ích công cộng của Việt Nam trong trường hợp có quốc gia nước ngoài từ chối công nhận phán quyết của Trọng tài Việt Nam với lý do giữa Việt Nam và nước đó chưa có điều ước quốc tế điều chỉnh vấn đề này bởi lẽ quan hệ giữa các quốc gia được thiết lập trên nguyên tắc bình đẳng, vì vậy, khi một quốc gia đã từ chối công nhận phán quyết của Trọng tài Việt Nam thì Việt Nam có quyền từ chối công nhận phán quyết của Trọng tài quốc gia đó trên cơ sở có đi có lại. Thực tiễn áp dụng nguyên tắc có đi có lại 
lại cho thấy để nguyên tắc này giữa các nước liên quan phải có văn bản thoả thuận về việc áp dụng nguyên tắc với nhau.

Cơ chế cụ thể áp dụng nguyên tắc có đi có lại được quy định tại Luật tương trợ tư pháp 2007 và các văn bản hướng dẫn thi hành. Cụ thể, Khoản 1 Điều 66 Luật Tương trợ tư pháp 2007 quy định Bộ Ngoại giao có trách nhiệm chủ trì phối hợp với các bộ, ngành có liên quan xem xét, quyết định áp dụng nguyên tắc có đi có lại trong quan hệ tương trợ tư pháp với nước hữu quan và định kỳ thông báo với Bộ Tư pháp tình hình áp dụng nguyên tắc có đi có lại trong quan hệ tương trợ tư pháp với nước hữu quan. Điều 7 Nghị định số 92/2008/NĐ-CP không quy định chi tiết thêm. Các vấn đề cụ thể liên quan đến việc áp dụng nguyên tắc có đi có lại chỉ được quy định tương đối chi tiết tại Thông tư liên tịch số 15/2011/TTLT-BTP-BNGTANDTC ngày 15/9/2011 của Bộ Tư pháp, Bộ Ngoại giao và Toà án Nhân dân tối cao về "Hướng dẫn áp dụng mọt số quy định về tương trợ tu pháp trong linh vưc dân sư của Luật Tưong trọ tu pháp". Thông tư số 12/2016/TTLT-BTP-BNG-TANDTC ngày 19/10/2016 "Quy định về trình tụ, thủ tuc tương trọ" tư pháp trong lĩnh vưc dân sụ" thay thế Thông tư số 15/2011/TTLT-BTP-BNGTANDTC đã bỏ hầu hết các quy định trên, chỉ quy định ngắn gọn tại Điều 5 về “Áp dụng nguyên tắc có đi có lại trong tuoong trợ tu pháp về dân sư" hai trường hợp cơ quan có thẩm quyền Việt Nam có thể từ chối thực hiện tương trợ tư pháp về dân sự cho nước ngoài trên cơ sở nguyên tắc có đi có lại: Khi có căn cứ cho thấy phía nước ngoài không thực hiện tương trợ tư pháp về dân sự cho Việt Nam; Khi việc thực hiện tương trợ tư pháp đó trái với các nguyên tắc cơ bản của pháp luật Việt Nam.

2.3. Điều kiện công nhận và cho thi hành tại Việt Nam phán quyết của Trọng tài nước ngoài

Theo Điều 425 Bộ luật Tố tụng dân sự 2015 về "Quyền yêu cầu công nhận và cho thi hành hoặc không công nhận bản án, quyết định dân sự của Tòa án nước ngoài; công nhận và cho thi hành phán quyết của Trọng tài nước ngoài” thì có ba điều kiện đối với việc công nhận và cho thi hành tại Việt Nam phán quyết của Trọng tài nước ngoài:

Thư nhất, điều kiện về tư cách của người nộp đơn yêu cầu công nhận và cho thi hành. Theo khoản 1 Điều 425 Bộ luật Tố tụng dân sự 2015 thì người nộp đơn yêu cầu phải là "người được thi hành hoặc nguời đại diện hợp pháp của họ". Theo quy định này, chỉ có người được thi hành trong phán quyết của Trọng tài nước ngoài mới có quyền nộp đơn yêu cầu công nhận và cho thi hành phán quyết đó tại Việt Nam. Tuy nhiên, khoản 1 Điều 451 Bộ luật Tố tụng dân sự 2015 quy định điều kiện về thời hạn nộp đơn yêu cầu lại quy định chủ thể có quyền nộp đơn yêu cầu bao gồm "người được thi hành, người có quyền, lợi ich hợp pháp liên quan hoặc nguời đại diện hơp pháp của họ". Như vậy, phạm vi chủ thể được nộp đơn yêu cầu theo khoản 1 Điều 451 lại rộng hơn quy định tại khoản 1 Điều 425 và trên thực tiễn sẽ rất khó giải quyết yêu cầu công nhận và cho thi hành phán quyết của Trọng tài nước ngoài nếu rơi vào trường hợp này do hai chủ thể "người được thi hành" và "người có quyền, lợi ich hơp pháp liên quan" là hai chủ thể khác nhau và trong Bộ luật Tố tụng dân sự 2015 chưa có quy định nào định nghĩa "người có quyền, lợi ich hơp pháp liên quan”. Tại khoản 3 Điều 68 Bộ luật Tố tụng dân sự 2015 có quy định về "Người có quyền lợi, nghĩa vu liên quan" mà không phải là "người có quyền, lợi ich hơp pháp liên quan". Như vậy, quy định của khoản 1 Điều 451 về "người có quyền, lợi ich hợp pháp liên quan" cần phải được làm rõ.

Thư hai, điều kiện về nơi cư trú của người phải thi hành. Theo khoản 1 Điều 425 thìngười được thi hành hoặc người đại diện hợp pháp của họ có quyền yêu cầu Tòa án Việt Nam công nhận và cho thi hành tại Việt Nam phán quyêt của Trọng tài nước ngoài, nếu tại thời điểm người được thi hành nộp đơn "cá nhân phải thi hành cu trú, làm việc tại Việt Nam hoặc co quan, tổ chức phải thi hành có trụ sở chính tại Việt Nam". 
Cả hai điều kiện về tư cách của người nộp đơn yêu cầu và điều kiện về nơi cư trú của người phải thi hành phải đi song hành với nhau và là quy định kế thừa khoản 1 Điều 344 Bộ luật Tố tụng dân sự 2004. Theo khoản 1 Điều 344 Bộ luật Tố tụng dân sự 2004 thì hai điều kiện này áp dụng chung cho cả công nhận và cho thi hành tại Việt Nam phán quyết của Trọng tài nước ngoài, bản án, quyết định dân sự của Toà án nước ngoài.

Thú $b a$, điều kiện về tài sản của người phải thi hành. Theo khoản 1 Điều 425 thìngười được thi hành hoặc người đại diện hợp pháp của họ có quyền yêu cầu Tòa án Việt Nam công nhận và cho thi hành tại Việt Nam phán quyết của Trọng tài nước ngoài, nếu "tài sản liên quan đến việc thi hành phán quyết của Trọng tài nuớc ngoài có tại Việt Nam vào thời điểm yêu cầu". Đây cũng là quy định kế thừa khoản 1 Điều 344 Bộ luật Tố tụng dân sự 2004.

Như vậy, việc Bộ luật Tố tụng dân sự 2015 tiếp tục kế thừa các điều kiện công nhận và cho thi hành phán quyết của Trọng tài nước ngoài của Bộ luật Tố tụng dân sự 2004 chứng minh tính phù hợp của các quy định này với tình hình thực tiễn của Việt Nam những năm vừa qua.

\subsection{Cơ quan có thẩm quyền nhận đơn yêu cầu công nhận và cho thi hành tại Việt Nam phán quyết của Trọng tài nước ngoài}

Theo quy định tại khoản 1 Điều 451 Bộ luật Tố tụng dân sự 2015 thì "người được thi hành, người có quyền, lợi ích hợp pháp liên quan hoặc người đại diện hợp pháp của họ có quyền gửi đơn đến Bộ Tư pháp Việt Nam theo quy định của điều ước quốc tế mà Cộng hòa xã hội chủ nghĩa Việt Nam là thành viên hoặc Tòa án có thẩm quyền của Việt Nam theo quy định của Bộ luật này trong trường hợp điều ước quốc tế mà Cộng hòa xã hội chủ nghĩa Việt Nam là thành viên không quy định hoặc không có điều ước quốc tế liên quan để yêu cầu Tòa án công nhận và cho thi hành tại Việt Nam phán quyết đó". Như vậy, có hai cơ quan có thẩm quyền nhận đơn yêu cầu công nhận và cho thi hành phán quyết của Trọng tài nước ngoài:
- Trường hợp giữa Việt Nam và nước mà Hội đồng trọng tài tuyên phán quyết đều là thành viên của điều ước quốc tế có liên quan thì cơ quan có thẩm quyền nhận đơn là Bộ Tư pháp. Việt Nam đã là thành viên của Công ước New York 1958 nên đối với các phán quyết của Trọng tài những nước là thành viên Công ước New York thì đơn yêu cầu công nhận nộp tại Bộ Tư pháp. Trong thời hạn 05 ngày làm việc, kể từ ngày nhận được đơn yêu cầu và giấy tờ, tài liệu Bộ Tư pháp phải chuyển cho Tòa án có thẩm quyền.

- Trường hợp giữa Việt Nam và quốc gia mà Hội đồng trọng tài tuyên phán quyêt không có điề̀ ước quốc tế liên quan hoặc có điều ước quốc tế liên quan nhưng không quy định vấn đề công nhận phán quyết của Trọng tài nước ngoài thì cơ quan có thẩm quyền nhận đơn là Toà án có thẩm quyền theo quy định của Bộ luật Tố tụng dân sự 2015. So với Bộ luật Tố tụng dân sự 2004 thì quy định này có sự điều chỉnh. Theo quy định tại khoản 1 Điều 364 Bộ luật Tố tụng dân sự 2004 thì chỉ có Bộ Tư pháp nhận đơn và hồ sơ yêu cầu công nhận và cho thi hành tại Việt Nam phán quyết của Trọng tài nước ngoài.

So với Bộ luật Tố tụng dân sự 2004 thì quy định này có sự điều chỉnh. Theo quy định tại khoản 1 Điều 364 Bộ luật Tố tụng dân sự 2004 thì chỉ có Bộ Tư pháp nhận đơn và hồ sơ yêu cầu công nhận và cho thi hành tại Việt Nam phán quyết của Trọng tài nước ngoài.

\section{Những vấn đề phát sinh từ thực tiễn áp dụng quy định của Bộ luật Tố tụng dân sự 2015 về công nhận và cho thi hành tại Việt Nam phán quyết của Trọng tài nước ngoài và kiến nghị góp phần nâng cao hiệu quả điều chỉnh của pháp luật}

\subsection{Phán quyết của Trọng tài nước ngoài được công nhận tại Việt Nam}

Quy định của Bộ luật Tố tụng dân sự 2015 về phán quyết của Trọng tài nước ngoài được công nhận và cho thi hành tại Việt Nam phải là "phán quyết cuối cùng" giải quyết thực chất vụ tranh chấp giữa các bên có liên quan là quy 
định kế thừa Bộ luật Tố tụng dân sự 2004 và phù hợp với Công ước New York 1958. Tuy nhiên, việc quy định Việt Nam chỉ công nhận và cho thi hành phán quyết của Trọng tài nước ngoài về các tranh chấp phát sinh từ quan hệ pháp luật thương mại theo Quyết định số 453/QĐ-CTN ngày 28/7/1995 của Chủ tịch nước về việc gia nhập Công ước New York đã thu hẹp phạm vi các phán quyết của Trọng tài nước ngoài được công nhận và cho thi hành tại Việt Nam. Đối chiếu với quy định tại Điều 2 về "Thẩm quyền giải quyết các tranh chấp của Trọng tài" của Luật Trọng tài thương mại 2010 cho thấy phạm vi các vụ việc thuộc thẩm quyền giải quyết của Trọng tài thương mại là rộng hơn vì theo khoản 3 Điều 2 thì Trọng tài thương mại Việt Nam có thẩm quyền giải quyết "Tranh chấp khác giữa các bên mà pháp luật quy định được giải quyết bằng Trọng tài”. Vào thời điểm gia nhập Công ước New York 1958 cũng như ban hành Quyết định số 453/QĐ-CTN ngày 28/7/1995 Việt Nam đang áp dụng các văn bản Nghị định số 116/CP ngày 5 tháng 9 năm 1994 của Chính phủ về tổ chức và hoạt động của Trọng tài kinh tế; Quyết định số 204/TTg ngày 28 tháng 4 năm 1993 của Thủ tướng Chính phủ về tổ chức Trung tâm Trọng tài quốc tế Việt Nam; Quyết định số 114/TTg ngày 16 tháng 2 năm 1996 của Thủ tướng Chính phủ về mở rộng thẩm quyền giải quyết các tranh chấp của Trung tâm Trọng tài quốc tế Việt Nam. Thẩm quyền của Trung tâm Trọng tài quốc tế Việt Nam đối với các tranh chấp thương mại quốc tế theo các văn bản trên rất hẹp, chỉ bao gồm "các tranh chấp phát sinh tù các quan hệ kinh tế quốc tế nhu các hợp đồng mua bán Ngoại thuoong, các hợ đồng đầu tu, du lịch, vận tải và bảo hiểm quốc tế, chuyển giao công nghệ, tín dụng và thanh toán quốc tế ...”. Trong bối cảnh kinh tế - xã hội giai đoạn đó cũng như bối cảnh lập pháp của quốc gia thì khi gia nhập Công ước New York 1958 Việt Nam bảo lưu phạm vi áp dụng công ước là đều tất yếu. Tuy nhiên, trong bối cảnh hội nhập quốc tế hiện nay, để phù hợp với các chuẩn mực pháp lý quốc tế cũng như tạo điều kiện thuận lợi cho hoạt động của các Trung tâm trọng tài thương mại Việt
Nam cũng như mở rộng phạm vi các phán quyết của Trọng tài nước ngoài được công nhận và cho thi hành tại Việt Nam, phù hợp với Công ước New York 1958, cần nghiên cứu rút lại bảo lưu khi gia nhập Công ước New York 1958 theo Quyết định số 453/QĐ-CTN ngày 28/7/1995 của Chủ tịch nước về việc gia nhập Công ước New York. Theo điểm (ii) Điều 2 của Quyết định thì Việt Nam sẽ "Chỉ áp dụng Công uớc đối với các tranh chấp phát sinh tù các quan hệ pháp luật thuơng mại".

Đối với vấn đề "phán quyết trọng tài phi chính thiúc", trên thế giới đến thời điểm hiện tại chỉ có Italia quy định chính thức trong luật về loại phán quyết này, trong khi các quốc gia khác đều, thậm chí còn quy định rõ không công nhận phán quyết phi chính thức, điển hình là Cộng hoà liên bang Đức [1]. Theo quan điểm tác giả, chưa cần thiết xây dựng quy định về công nhận phán quyết phi chính thức của Trọng tài nước ngoài trong pháp luật Việt Nam bởi lẽ, như đã nêu, trên thế giới mới chỉ có pháp luật Italia đặt ra vấn đề công nhận và cho thi hành loại phán quyết này. Bên cạnh xuất đó, xuất phát từ bối cảnh thực tế của Việt Nam đã là thành viên của Công ước New York 1958 chỉ quy định về phán quyết trọng tài chính chức và thực tiễn cũng chưa xuất hiện yêu cầu thi hành phán quyết trọng tài phi chính thức tại Việt Nam.

\subsection{Nguyên tắc có đi có lại trong công nhận và cho thi hành phán quyết của Trọng tài nước ngoài}

Việc Bộ luật Tố tụng dân sự 2015 tiếp tục kế thừa quy định về nguyên tắc có đi có lại của Bộ luật Tố tụng dân sự 2004 xuất phát từ vai trò cần thiết của nguyên tắc trong bối cảnh chưa có nhiều điều ước quốc tế liên quan đến tương trợ tư pháp nói chung, công nhận và cho thi hành phán quyết của Trọng tài nói riêng. Nguyên tắc có đi có lại về bản chất là những trường hợp cụ thể trên thực tế cơ quan có thẩm quyền của các quốc gia quyết định việc tương trợ tư pháp lẫn nhau khi giữa hai quốc gia chưa có điều ước quốc tế ràng buộc nghĩa vụ này. Tuy nhiên, nếu việc áp dụng nguyên tắc này không theo nguyên tắc chung và khó dự đoán trước sẽ làm 
cho các quan hệ dân sự có yếu tố nước ngoài kém ổn định và các bên chủ thể tham gia quan hệ có thể khó bảo vệ được lợi ích hợp pháp của mình. Để khắc phục, các quốc gia đã tiến hành ký kết các thoả thuận về áp dụng nguyên tắc có đi có lại để nâng cao hiệu quả áp dụng pháp luật. Việc ký kết các điều ước về áp dụng nguyên tắc có đi có lại cần phải hết sức thận trọng bởi khi đã là cam kết quốc tế thì quốc gia phải tuân thủ. Vì vậy, để đảm bảo việc ký kết được thực hiện theo một định hướng thống nhất, một mặt có thể áp dụng nguyên tắc có đi có lại trên thực tế để bảo vệ lợi ích hợp pháp của chủ thể Việt Nam mặt khác phải bảo được trật tự công cũng như chính sách đối ngoại của Việt Nam thì cần có một cơ quan đảm nhận việc theo dõi, tổng kết danh sách các quốc gia đã áp dụng hoặc thoả thuận áp dụng nguyên tắc có đi có lại với Việt Nam đề đề xuất ký kết hiệp định về áp dụng nguyên tắc có đi có lại với Việt Nam.

Bên cạnh đó, cơ chế cụ thể để áp dụng nguyên tắc có đi có lại trên thực tế là vấn đề cần phải tiếp tục nghiên cứu hoàn thiện. Theo báo cáo của Toà án nhân dân thành phố Hồ Chí Minh, khi gặp các trường hợp cần áp dụng nguyên tắc có đi có lại, thẩm phán giải quyết vụ việc thường có văn bản hỏi ý kiến của Bộ Tư pháp, Bộ Ngoại giao, Toà án nhân dân tối cao và vì vậy thời gian giải quyết vụ việc thường kéo dài, không đảm bảo thời hạn tố tụng. Cũng có Thẩm phán đã đề nghị người có đơn yêu cầu phải chứng minh giữa Việt Nam và nước có liên quan đã từng áp dụng nguyên tắc có đi có lại [7]. Ví dụ: Trong việc giải quyết yêu cầu của Công ty TNHH Hanjin Shipping công nhận và cho thi hành tại Việt Nam Quyết định số 2017 HaHapBnakruptcy ngày 17/02/2017 của Tòa án Hàn Quốc về việc phá sản Công ty Hanjin Shipping vừa phân tích ở trên Toà án nhân dân thành phố Hồ Chí Minh đã có Công văn số 372/TATP-TKT ngày 17/01/2018 gửi Bộ Tư Pháp và Công văn số $1625 /$ TATP-TKT ngày 02/4/2018 gữi Tòa án nhân dân Tối cao với nội dung: "Giũ̃a hai nước Cộng hòa Xã hội Chủ nghĩa Việt Nam và Đại hàn Dân Quốc chua ký kết Hiệp định tuoong trọ tu pháp trong lĩnh vục dân sự và thuoong mại, chua có thỏa thuận tiền lệ về áp dụng nguyên tắc có đi có lại. Vì vậy, trong trường hơp này có được áp dụng theo nguyên tắc có đi có lại để chấp nhận đơn yêu cầu của Hanjin Shipping Co.,Ltd hay không?". Và Bộ Tư pháp đã có Công văn số 1380/BTPPLQT ngày 24/4/2018 đề nghị Tòa án nhân dân Thành phố Hồ Chí Minh tham khảo thêm Công văn số 4609/BTP-PLQT ngày 03/10/2017 của Bộ Tư pháp trao đổi với Tòa án nhân dân Tối cao về vấn đề này. Theo nội dung công văn trên, khi giải quyết, Tòa án cần chú ý đến vấn đề đương sự chứng minh nguyên tắc có đi có lại được áp dụng giữa hai nước.

Như vậy, vấn đề phát sinh từ thực tiễn áp dụng nguyên tắc có đi có lại chính là những quy định cụ thể để áp dụng nguyên tắc này về cơ quan có thẩm quyền quyết định áp dụng, cơ chế áp dụng,... Theo khoản 1 Điều 66 Luật tương trợ tư pháp 2007 thì Bộ Ngoại giao là cơ quan có thẩm quyền quyết định việc áp dụng hay từ chối áp dụng nguyên tắc có đi có lại theo đề nghị của cơ quan có thẩm quyền nước ngoài. Tuy nhiên, thực tiễn cho thấy vai trò của Bộ Tư pháp trong vấn đề này là rõ ràng hơn xuất phát từ chức năng, nhiệm vụ cũng như đội ngũ chuyên gia pháp lý đang làm việc tại Bộ Tư pháp. Bên cạnh đó, Luật Tương trợ tư pháp năm 2007 (khoản 4 Điều 62) cũng đã quy định Bộ Tư pháp có trách nhiệm đề xuất việc ký kết, gia nhập và thực hiện điều ước quốc tế về tương trợ tư pháp; kiến nghị sửa đổi, bổ sung và hoàn thiện pháp luật Việt Nam về tương trợ tư pháp. Vì vậy, theo quan điểm tác giả, cần giao thẩm quyền quyết định áp dụng nguyên tắc có đi có lại trên thực tế cho Bộ Tư pháp. Bộ Ngoại giao sẽ là đầu mối để thông báo kết quả giải quyết với cơ quan có thẩm quyền nước ngoài sau khi nhận được kết quả từ Bộ Tư pháp. Việc giao Bộ Tư pháp quyền quyết định áp dụng nguyên tắc có đi có lại sẽ góp phần đảm bảo tính pháp lý của kết quả áp dụng pháp luật cũng như phù hợp với yêu cầu của thực tiễ் bởi lẽ Bộ $T u ̛$ pháp là cơ quan trực tiếp tham mưu cho Chính phủ thẩm định các vấn đề liên quan đến pháp lý trong hoạt động của Chính phủ nói chung. Việc tập trung thẩm quyền quản lý, quyết định các 
vấn đề liên quan đến nguyên tắc có đi có lại còn góp phần đảm bảo tính thống nhất của việc áp dụng nguyên tắc trên thực tiễn, chấm dứt tình trạng không thống nhất giữa các Toà án có thẩm quyền của Việt Nam khi giải quyết yêu cầu công nhận và cho thi hành tại Việt Nam phán quyết của Trọng tài nước ngoài như đã từng xảy ra trong giai đoạn áp dụng luật Tố tụng dân sự 2004 cũng như thời gian gần đây khi áp dụng Bộ luật Tố tụng dân sự 2015 [8].

\section{3. Điều kiện công nhận và cho thi hành phán quyết của Trọng tài nước ngoài}

Như đã phân tích, sự khác nhau giữa khoản 1 Điều 425 khoản 1 Điều 451 Bộ luật Tố tụng dân sự 2015 sẽ gây ra khó khăn trên thực tế bởi người được thi hành và người có quyền, lợi ích hợp pháp liên quan là hai chủ thể khác nhau và điều này đã được quy định rất cụ thể trong các văn bản pháp luật hiện hành có liên quan. Theo đoạn 2 khoản 1 Điều 68 Bộ luật Tố tụng dân sự 2015 thì "Đương sư trong việc dân sư là co" quan, tổ chức, cá nhân bao gồm người yêu cầu giải quyết việc dân sư và người có quyền lợi, nghĩa vu liên quan". Còn theo khoản 2 Điều 3 Luật Thi hành án dân sự 2008 (sửa đổi, bổ sung 2014) thì "Người được thi hành án là cá nhân, cơ quan, tổ chức được hưởng quyền, lơi ich trong bản án, quyết định được thi hành". Theo khoản 4 Điều 3 Luật Thi hành án dân sự 2008 (sửa đổi, bổ sung 2014) thì "Người có quyền lợi, nghĩa vu liên quan là cá nhân, cơ quan, tổ chức có quyền lợi, nghĩa vu liên quan trục tiếp đến viẹc thưc hiện quyền, nghĩa vu thi hành án của đưong sụ". Như vậy, đây là hai chủ thể có tư cách khác nhau trong quan hệ pháp luật thi hành án dân sự, bao gồm cả quan hệ thi hành phán quyết của Trọng tài nước ngoài được công nhận và cho thi hành tại Việt Nam. Sự khác biệt này sẽ làm cho cơ quan có thẩm quyền lúng túng khi nhận đơn yêu cầu từ các chủ thể có yêu cầu bởi lẽ một trong những căn cứ để Toà án trả lại đơn yêu cầu giải quyết việc dân sự quy định tại điểm a khoản 1 Điều 364 Bộ luật Tố tụng dân sự 2015 là "Người yêu cầu không có quyền yêu cầu”. Đối với trường hợp "ngườ có quyền, lợi ích hợp pháp liên quan" nộp đơn yêu cầu công nhận và cho thi hành phán quyết của Trọng tài nước ngoài nếu áp dụng khoản 1 Điều 425 Bộ luật Tố tụng dân sự 2015 thì Toà án phải trả lại đơn yêu cầu, nhưng nếu áp dụng khoản 1 Điều 451 Bộ luật Tố tụng dân sự 2015 thì Toà án phải nhận đơn yêu cầu.

Từ bối cảnh như trên, xuất phát từ quan điểm tạo điều kiện thuận lợi cho việc thực hiện quyền yêu cầu của chủ thể có liên quan cũng như mở rộng phạm vi các phán quyết của Trọng tài nước ngoài được công nhận và cho thi hành tại Việt Nam, phù hợp với Công ước New York 1958, tác giả đề xuất sửa đổi quy định tại khoản 1 Điều 425 Bộ luật Tố tụng dân sự 2015 tương đồng với quy định tại khoản 1 Điều 451 Bộ luật Tố tụng dân sự 2015, theo đó, chủ thể có quyền nộp đơn quyền nộp đơn yêu cầu công nhận và cho thi hành phán quyết của Trọng tài nước ngoài bao gồm "người được thi hành, người có quyền, lợi ich hợp pháp liên quan hoạc người đại diện hợp pháp của họ".

3.4. Co quan có thẩm quyền nhận đơn yêu cầu công nhận và cho thi hành phán quyết của Trọng tài nuoóc ngoài

Theo quy định của khoản 1 Điều 451 Bộ luật Tố tụng dân sự 2015 thì có hai cơ quan có thẩm quyền nhận đơn yêu cầu công nhận và cho thi hành tại Việt Nam phán quyết của Trọng tài nước ngoài là Bộ Tư pháp và Toà án nhân dân có thẩm quyền theo quy định của Chương III Phần thứ nhất Bộ luật Tố tụng dân sự 2015. Đây là một trong những điểm sửa đổi của $B o ̣ ̂$ luật Tố tụng dân sự 2015 so với Bộ luật Tố tụng dân sự 2004 (sửa đổi, bổ sung 2011). Tuy nhiên, xuất phát từ thực tiễn giai đoạn áp dụng Bộ luật Tố tụng dân sự 2015 cho thấy Toà án nhân dân cấp tỉnh không biết khi nào nhận đơn yêu cầu của đương sự, khi nào nhận đơn yêu cầu từ Bộ Tư pháp [9]. Từ thực tiễn này cũng như mong muốn tạo điều kiện thuận lợi cho hoạt động công nhận và cho thi hành tại Việt Nam phán quyết của Trọng tài nước ngoài, 
thống nhất với cơ chế cụ thể áp dụng nguyên tắc có đi có lại như để xuất ở trên Mục 2.2, tác giả đề xuất cần khôi phục quy định tại khoản 1 Điều 364 Bộ luật Tố tụng dân sự 2004 (sửa đổi, bổ sung 2011). Theo đó, chỉ có Bộ Tư pháp nhận đơn và hồ sơ yêu cầu công nhận và cho thi hành tại Việt Nam phán quyết của Trọng tài nước ngoài. Việc áp dụng quy định này sẽ đảm bảo một đầu mối nhận đơn thống nhất cũng như công tác hướng dần nghiệp vụ chuyên môn trong trường hợp cần thiết, công tác thống kê, tổng hợp tình hình thực tế công nhận và cho thi hành phán quyết của Trọng tài nước ngoài được thuận lợi, tạo điều kiện cho công tác tổng kết áp dụng pháp luật, phát hiện các hạn chế của pháp luật, đề xuất cơ chế áp dụng pháp luật hiệu quả sẽ nhanh chóng, đạt được kết quả cao.

\section{Kết luận}

Việc ban hành Bộ luật Tố tụng dân sự 2015 thay thế cho Bộ luật Tố tụng dân sự 2004 (sửa đổi, bổ sung 2011) là bước tiến bộ của pháp luật tố tụng dân sự Việt Nam nói chung, pháp luật điều chỉnh vấn đề công nhận và cho thi hành tại Việt Nam phán quyết của Trọng tài nước ngoài nói riêng. Đối với vấn đề công nhận và cho thi hành tại Việt Nam phán quyết của Trọng tài nước ngoài, bên cạnh việc kế thừa các nội dung phù hợp, Bộ luật Tố tụng dân sự 2015 cũng đã sửa đổi các quy định không phù hợp, bổ sung các quy định còn thiếu của của Bộ luật Tố tụng dân sự 2004 (sửa đổi, bổ sung 2011). Tuy nhiên, quá trình áp dụng các quy định này vào thực tiễn trong thời gian qua đã đặt ra những vấn đề cần phải tiếp tục nghiên cứu, hoàn thiện liên quan đến Phán quyết của Trọng tài nước ngoài được công nhận tại Việt Nam; Nguyên tắc công nhận và cho thi hành tại Việt Nam phán quyết của Trọng tài nước ngoài; Điều kiện công nhận và cho thi hành tại Việt Nam phán quyết của Trọng tài nước ngoài; Cơ quan có thẩm quyền nhận đơn yêu cầu công nhận và cho thi hành tại Việt Nam phán quyết của Trọng tài nước ngoài nhằm nâng cao hiệu quả điều chỉnh của pháp luật trong giai đoạn sắp tới. Điều này sẽ góp phần hoàn thiện hệ thống quy phạm pháp luật điều chỉnh các quan hệ dân sự có yếu tố nước ngoài của Việt Nam nói chung, tạo hành lang pháp lý thuận lợi cho quá trình hội nhập quốc tế của Việt Nam.

\section{Tài liệu tham khảo}

[1] Lê Nguyễn Gia Thiện - Lê Nguyễn Gia Thuận, Phán quyết trọng tài phi chính thức: Quy định của pháp luật Italia, thực tiễn thi hành tại Đức và một số đề xuất cho Việt Nam, Tạp chí Nghiên cứu Lập pháp, 5, (2019) tr. 59, 64.

[2] Bành Quốc Tuấn, Giáo trình Tư pháp quốc tế, NXB Chính trị Quốc gia - Sự thật, Hà Nội, 2017, tr. $334-335$.

[3] Trường Đại học Luật Hà Nội, Giáo trình Tư pháp quốc tế, NXB Công an Nhân dân, 1999, tr. 317, 348.

[4] Trường Đại học Luật Thành phố Hồ Chí Minh, Giáo trình Tư pháp quốc tế (Phần chung), NXB Hồng Đức - Hội Luật gia Việt Nam, 2014, tr. 208.

[5] Khoa Luật - Đại học Quốc gia Hà Nội, Giáo trình Tư pháp Quốc tế, NXB Đại học Quốc gia Hà Nội, 2013, tr. 468, 516.

[6] Bành Quốc Tuấn, Công nhận và cho thi hành tại Việt Nam bản án, quyết định dân sự của Toà án nước ngoài (Sách chuyên khảo), Nhà xuất bản Chính trị Quốc gia - Sự thật, Hà Nội, 2015, tr. 123.

[7] Nguyễn Thị Thuỳ Dung, Thực tiễn giải quyết yêu cầu công nhận và cho thi hành bản án, quyết định của Toà án nước ngoài, quyết định của cơ quan có thẩm quyền nước ngoài tại Toà án Nhân dân Thành phố Hồ Chí Minh, Tài liệu Hội nghị Tập huấn Công nước New York 1958 về Công nhận và cho thi hành phán quyết của Trọng tài nước ngoài, Thành phố Hồ Chí Minh, tháng 01/2019.

[8] Bành Quốc Tuấn, Áp dụng nguyên tắc có đi có lại trong công nhận và cho thi hành tại Việt Nam bản án, quyết định dân sự của nước ngoài, Tạp chí Nghiên cứu Lập pháp, 18 (2017) 09-13.

[9] Bộ Tư pháp - Đại sứ quán Anh tại Hà Nội, Sổ tay hướng dẫn thực hiện Công ước New York 1958 về công nhận và cho thi hành phán quyết trọng tài nước ngoài, NXB Dân Trí, Hà Nội (2017) tr. 45. 